\title{
Remapping the organ donation ethical climate: a care ethics consideration
}

\begin{abstract}
Organ donation has gained much attention as the need for transplant exceeds the supply of organs. Various proposals have been put forward to address the organ shortage challenge, ranging from offering incentives to donors, addressing family refusals to donations and instituting presumed consent laws. Presumed consent as the favoured approach has not been universally effective in increasing actual transplants despite its appeal. Few considerations have been given to the broader ethical climate influencing the organ donation debate. This paper examines the ethical climate surrounding organ donation and identifies the challenges existing within such environments. It explores care ethics and its application to the donation system, demonstrating how it can influence the organ donation phases. The conclusion drawn from the analysis is that a caring ethical climate in the pre, during and post-transplant system respects donor autonomy, addresses family reluctance to agree to donation, facilitates the needs of the donee and creates an environment that promotes non-maleficence for all stakeholders.

(159 words)
\end{abstract}

Keywords: ethical climate, organ donation, presumed consent, relational, care ethics, family

\section{INTRODUCTION}

\section{A. The Organ Donation Challenge}

The recent shift towards implementing a presumed consent model in England has precipitated the renewal of the organ donation debate. Responses towards the organ shortage challenge range from implementing presumed consent (Levitt 2015; Abouna 2008) to incentivising donors through priority lists or payment options (Cronin and Harris 2010; Wu and Fang 2013; Hobday 2015; Caplan 2016; Henderson and Gross 2017). Recent proposals include integrating organ donation conversations into advance care planning, and proposing 
advance commitments in honouring the donor's prior expressed donation (Saul 2012; Wispelaere and Stirton 2010). Other contributions focused on overcoming familial objections, and nudging families towards accepting donors' donation decision through positive reinforcement and indirect suggestions (Sharif and Moorlock 2018; M'hamdi et al, 2017; Groot et al, 2015).

A presumed consent model is a primarily favoured approach despite the entrenched altruistic notion of gift of life; thus raising questions regarding the authenticity of such donations (Guttman et al, 2016). Notwithstanding its appeal, it is far from ethically unproblematic and rife with criticisms, notably on its effectiveness in overcoming organ shortage (Albertsen 2018; Hawkes 2018; Dalen and Henkens 2014; Saunders 2010; Verheijde et al, 2009; Bilgel 2013). Critics often point to considerably long transplant waiting lists in presumed consent jurisdictions, citing that legislation alone would not increase donor rates (Shepherd et al, 2014) while other objections include the lack of trust and certainty in such systems (McCartney 2017). A recent study in Wales on the impact of soft opt-out approach revealed no significant correlations between the approach and increases in organ donors (Noyes et al, 2019), thus reinforcing the lack of evidence of the perceived benefits of presumed consent (Parsons 2018; Nuffield Council on Bioethics 2018; Coppen 2010). Despite these criticisms, it is said to have generated some positive outcomes in raising donation awareness and recognising the challenges in supporting the successful implementation of the law (Albertsen 2018).

It is significant and timely to re-evaluate the organ donation debate from a conceptually pragmatic perspective, given the continuing efforts in advocating for opt-out programmes designed to increase organ donor rates (GODT 2016). Organ donation raises 
unique questions of altruism, autonomy and wider ethical challenges within the transplant process. Family refusals, arising from an ignorance of the donor's donation decision have often been cited as the primary reason for overriding prior expressed donations (NHSBT 2014; Price 2011). In response to family refusals, there were suggestions for implementing behavioural changes in people's attitudes towards organ donation and transforming end-oflife practices towards a more supportive system for families and transplant teams (NHSBT 2014), signifying family-specialist partnerships as more aligned with higher consent rates to donate (Hulme et al, 2016). This indicates the need to bridge the ineffective engagements between the stakeholders - donors, families, healthcare providers, transplant teams and donees towards a more streamlined process.

The stakeholders identified above, in particular, operate within a climate that is pregnant with pressures, constraints and competing interests. On one hand, from the donor's perspective, families and healthcare providers would like to ensure that healthcare provision remains and resolve familial conflicts in donation decision-making; while the other dimension consisting of transplant teams and donees are hopeful of successful transplants. The current ethical climate in organ donation based on a presumed consent approach is inadequate in mediating the relevant tensions, respecting donor autonomy and sustaining relations between donor families, donees and the clinical care and transplant teams. It is imperative to rethink the organ transplant architecture beyond pursuing a presumed consent approach under legal mandates or transplanting successful legal frameworks onto another distinct socio-legal environment. Rather, a change in the ethical climate for organ donation is essential. This paper builds on existing knowledge on ways to address the challenges of organ donation by remapping the donation process from a care ethics approach with 
recommendations to improve each aspect in the donation process, consequently enriching the understanding of the ethical framework and their practical implications.

Section I has identified the challenges with organ donation, and the existing responses to address them. Section IIA examines the meaning of ethical climate, particularly its use in healthcare and its application in the organ transplant context. Sections IIB and IIC evaluate care ethics theory and advance its suitability to organ donation. Section IID illustrates the application of care theory through the three cycles of the donation process, demonstrating its potential influence in shaping the donation ethical climate. The focus is on donation after death rather than living donors, as the former generates contentious issues at the donation point. The aim of the paper is to show that an ethical climate that is premised on care ethics respects donor autonomy, and supports families in the donation journey. It also highlights the implications for law and clinical practice and offers suggestions to incorporate a care-driven approach towards creating an ethical climate conducive for organ donation.

\section{REMAPPING THE ETHICAL CLIMATE OF ORGAN DONATION}

\section{A. The Organ Donation Ethical Climate}

The ethical climate discourse primarily refers to organisational ethics and behaviours, indicating norms and cultures premised on what are acceptable or objectionable (Arnaud and Schminke 2012; Martin and Cullen 2006; Tenbrunsel et al, 2003). It denotes procedures that govern ethical issues which are applied consistently across the organisation, and reinforced through training and communication (Kuntz et al, 2013). Victor and Cullen (1988) introduced the ethical climate concept that served as foundations for ethical actions, drawn from organisation and economic theories. They identified five themes in ethical climate: caring, 
independence, rules (internal, organisational rules), instrumentalism, and law and codes (professional codes of conduct, national laws and legal rules), which demonstrated the influences of sociocultural environment, history and organisational forms in shaping the characteristics and decision-making in organisations. Ethical climate has been characterised as shared moral emotion, ethical efficacy and joint moral principles as essential elements in determining organisational ethical behaviour (Arnaud and Schminke 2012). Within the broader healthcare discourse, ethical climate featured on issues of justice, non-maleficence and beneficence in patient care and support, and the positive effect on healthcare professionals (Roybal 2017; Pillay 2015; Van den Bulcke et al, 2018; Lin et al, 2013). In nursing ethics jurisprudence (Silen et al, 2011; Koskenvueri et al, 2017; Bartholdson et al, 2016; Constantina 2018), studies have explored the ethical climates of hospitals and healthcare professionals in terms of identifying sources of moral distress, arising from ethical dilemma in delivering patient care and the lack of supportive doctor-nurse-patient partnerships (Lamiani et al, 2017; Numminen et al, 2015).

Although the ethical climate concept has its roots in organisational ethics and behaviours, it is highly relevant for organ donation, especially in considering the role of various stakeholders in shaping donation decisions, and addressing the distress experienced by donors' families and the healthcare and transplant teams. The organ donation process demands an acute need for sensitive communication and coordination between the stakeholders. To overlook this aspect means losing valuable signs of how ethical climate influences the success of organ donations. The nature of the relationship in the organ donation process is rarely purely between two parties - the doctors and the donor; rather it often involves the donors' families. The 'patient' is no longer strictly the donor, but the families, as they are affected by the donor's decision, thus it is paramount to care for them; for, by caring for them, we respect the donor's autonomy. Care here does not mean caving 
into family demands to decline donations against the donor's decision. Care, in this sense means helping families understand and accept the donor's wishes to donate for future donees.

The themes identified in Victor and Cullen's work, especially caring, is applicable to donation decision-making. A caring ethical climate responds to tensions and conflicts arising in the donation process, encourages trust, beneficence and non-maleficence, while balancing the ethical challenge of broaching organ donation at a distressing time with the donors' families. Building on the caring theme within the ethical climate discussion, the following section examines the way(s) in which care ethics is valuable for organ donation by evaluating the leading interpretations of care and identifies the application of a care ethics perspective that engages with some of the problematic issues arising in the donation process.

\section{B. An Ethics of Care}

Care ethics first emerged in the mid-1980s, having its origins in feminist ethics, led notably by Carol Gilligan, Nel Noddings, Joan Tronto, and Virginia Held. Care ethics developed in response to a predominantly “male/masculine” perspective that portrayed individualistic notions of self as the universally accepted assumption (Tong and Williams 2018). Feminist care ethicists recognised the universality of caring and advocated for a more “connected self” for human flourishing (ibid). Gilligan’s (1993) influential work on care ethics centred upon the ability to care for and protect others within the context of a relationship between self and others. This view posits creating an environment where human interactions underpin the fulfilment of most individual goals, not purely questions of autonomy and what people desire. Care extends beyond non-maleficence to beneficence towards self and others in sustaining a caring relationship that emphasised both relationships and responsibilities (Gilligan 1993). Noddings (1984) further articulated caring to include 
reciprocity, thus reinforcing the carer - cared-for relationship, premised on the argument that human caring and the memory of being cared-for underpinned ethical responses. Noddings' caring necessitates the carer's mental engrossment on the cared-for to promote the latter's wellbeing, while acting with rational objectivity, having regard to the objective needs of the cared-for. Warm acceptance and trust is essential, as without such attitudes, the cared-for is reduced to an object (65). Noddings, in response to criticisms that care ethics is inadequate in addressing social issues, maintained that social justice awareness developed from experiences acquired at home (Tong and Williams 2018; Sanders-Staudt 2019).

Similar to Gilligan and Noddings, Tronto’s (1993) concept of care encompassed human interactions, where caring is both a practice and a disposition, is continuous, and defined according to their cultural contexts $(102,103)$. Tronto outlined four interrelated phases of the caring process: caring about, taking care of, care-giving and care-receiving (105-108). These four phases of caring involves recognising a person's need (guided by processes of caring about and taking care of) and identifying ways to respond to, or to meet those needs, thus activating care giving and care receiving as authentic human interactions. The act of caring therefore involves both thought and action, supported by sufficient means $(108,110)$. Tronto, together with Fisher, further delineated the elements of care ethics as encompassing attentiveness, responsibility, competence, and responsiveness; characteristics that shape and “inform all aspects of a practitioner's moral life” (127). Responsibility requires people to look beyond legal and formal ties to understand the underlying causes for certain conditions to occur and "understanding what people should do for each other" (Tronto, 1993, 132, 133). Tronto's viewpoint on care is motivated by the central moral question of "how" rather than "what" do we best meet our caring responsibilities $(137,140)$. In rendering these moral elements into practice, Tronto illustrated that: 
...caring requires a deep and thoughtful knowledge of the situation, and of all of the actors' situations, needs and competencies...[t]hose who engage in a care process must make judgments: judgments about needs, conflicting needs, strategies for achieving ends, the responsiveness of care-receivers, and so forth. Care rests upon judgments that extend far beyond personal awareness...the kinds of judgments that I have described require an assessment of needs in a social and political, as well as a personal, context. (136-137)

Helga Kuhse (1997, 149) observed that Noddings' concept of care requiring the carer's engrossment as too onerous and suggested that "competent, professional physical care” is sufficient (149). Kuhse, recognising the evolving nature of care (145), proposed a "dispositional notion of care” as vital for good patient care and focused on being responsive to patient needs as unique individuals "rather than a malfunctioning organism” (150-152). A dispositional notion of care stems from recognising that basic ethical principle should consider both the "interests or well-being of all those affected by our actions” (171). This approach is analogous to Tronto's construction of care ethics as both a practice and a disposition. Kuhse further emphasised that autonomy is not antagonistic to relational concerns; rather in showing care for the person as a "relational being” we are respecting their autonomy (174).

Virginia Held (2006, 168) equally affirmed the relational aspect of society, allowing mutual respect of rights to thrive and creating healthy social relations. Held formulated care as both a practice and a value; premised on lived experiences, reason and emotion (23, 29). A caring person has "the appropriate motivations in responding to others or in providing care... and also participates adeptly in effective practices of care” (4). Held viewed that care should be present in the public sphere, for without care, justice cannot exist; similar to 
Noddings (119). Michael Slote (2007) broadened the care ethics from a gender-based approach in Gilligan's earlier work to apply to normative moral issues. Slote advocated that empathy, often neglected in care ethics is instrumental in expressing care and is a source of motivation to care for others. Slote also shared Kuhse's view on the complementary nature of caring and autonomy; for emphatic caring obliges people to respect others autonomy, understood in relational terms.

Recent studies reiterated important characteristics of human interactions such as “reciprocity, dependency, connectedness and asymmetry" which are entrenched in daily life (Pettersen 2011, 52, 53). The normative core value of care ethics includes "the universal commitment to human flourishing” which signifies active care interventions, including uncovering causes of harm in human relations towards promoting and maintaining caring relationships (Pettersen 2011, 54, 63). In exploring care ethics in current medical practice, Martinsen (2011), drawing from Gilligan’s interpretation of care, argued that modern medicine is inadequate in offering a sustainable care concept despite its centrality in medicine. The lack of active beneficent participation in a doctor-patient relationship caused harm $(176,178)$, consequently a deficiency in care triggers suffering in clinical encounters where the emotional needs are unmet in times of death and grief. This emphasis is relevant to organ donation where surgical procedures affect families and their healing process post donation.

An examination of the differing conceptions of care ethics reveals that care embodies several characteristics framed within networks of human relationships and interactions. They include a recognition of human inter-relatedness, mutual dependency and vulnerability that corresponds with life generally and clinical reality. A unique feature of care is the active 
actions driven by objectives that are oriented to the person's needs in a sustainable manner. These distinctive features require careful attention towards the motivations, emotions, and reasoning between self and others in human connections. The notion of care is flexible enough to accommodate the nuances existing in doctor-patient relationships that affect wider clinical practices. Above all, the breadth and depth of care ethics support and promote beneficence and non-maleficence, consequently encouraging the active exercise of autonomy according to the contextual needs of socio-legal issues.

\section{An Ethics of Care for Organ Donation}

An ethics of care creates a favourable ethical climate to the stakeholders in organ donation. In framing “caring” within ethical climate, Victor and Cullen (1988) characterised care as possessing elements of benevolence demonstrated by considerations of what is best for everyone in the company and for the other person (112). They highlighted that a caring climate "significantly affected employee satisfaction with the ethics of their company" (117), consequently influencing organisations to create a caring environment for the workforce (119). In contemporary bioethical environment that appears to emphasise autonomy, care is often inadvertently relegated as being abstract or obscure to implement. Organ donation is more than assenting to, and receiving donation. It involves a web of motivation for or against donating that interlinks the donor and future donees, with the family and the healthcare team. A care ethics approach departs from deontology that is premised on rights, for in organ donation, the "rights" of the donee cannot automatically triumph that of the donor or the donor family's refusal to donate after the donor's death; nor can utilitarian traditions of population good and sense of justice prevail over the donor in compelling them to donate. Presumed consent is broadly premised on utilitarian or communitarian values where there is the moral obligation to help fellow beings in need of organs. However, it neglects crucial 
aspects of care that is important in the donation "obligation”. The tension between the organ donor's decision to donate and the families' reluctance is augmented in situations where organs are not given as of right, but rather, as a gift in solidarity with those in need of organs. Care does not demand self-sacrifice for the benefit of others solely. Donors, in their donation decisions to benefit future donees may perceive it as perpetuating the cyclical nature of life and interconnecting beings, which corresponds to care ethics. This perspective reveals the value of donations to donors and families beyond donation decisions (Taylor et al 2018, 408). Care ethics thus exemplifies elements that value donor autonomy, their relational being, sustained by the good relationships with the healthcare teams, consequently engendering trust between the stakeholders. The care theory envisioned in organ donations reframes the relationship between the parties as connected and bound by the donor's decision. It translates the donor decision from a 'one-off' action to a process: from a journey that begins before the person decides to donate; during the process of determining death and extracting the organ and to post-donation matters as families deal with the grief and loss.

Care ethics generate essential considerations in organ donation, for example, what would be the best way to care for patients? How are relationships between donor-familydoctor-donee defined within a care theory? How does applying a care ethic to organ donation affect social behaviours and influence the law? As care ethicists view people as inter-related and interdependent beings; the decision to donate consequently affects the others in the "family unit". Emotions would surface especially when they deal with the death of loved ones, and simultaneous donation requests (particularly where organ viability and successful transplants are at stake). As such, nurturing the human relationships at this delicate stage would ideally need to happen before this event. The donor family's wellbeing is of significance, because the feelings of loss are often triggered regardless of the decision to 
donate. The loss may be amplified where the family is dealing with the loss 'twice' - first the death of the loved ones resulting in a loss of the relationship; followed by the possibility of organs being extracted away from the physical body. In essence, their orderly worldview has suddenly collapsed.

Prioritising human relationships is therefore significant in supporting the stakeholders. Sensitivity to the family reactions, compassionate and emphatic understanding is indispensable. Tronto's elements of attentiveness, competence, responsibility and responsiveness succinctly captured the underpinning actions of the care-givers which entailed substantial human interactions. The underlying causes for refusal should be evaluated sensitively and interpreted according to the context of that decision, because the reasons for refusal can comprise of multiple factors occurring within various sets of human relationships. These experiences collectively influence families' existence post donation. Care is demonstrated through actions that preserve and safeguard the dignity of and respect for the dead donors and their families in facilitating organ donation, while equally recognising the psychological strains on the healthcare team (Forsberg 2014, 278).

Care ethics were explored in investigating the lived experiences of families who were approached for organ donation (Casterle et al 2011). While the families accepted the consequence of benefiting potential donees, the requests were ill-timed as the donors were not perceived as dead by their families, or showing involuntary reflexes due to the life-like appearance fuelled by life-support machines; thus they were often unable to consent to donation towards others' benefit (234, 235; Isch 2007). Helping donors families accept the inevitability of death during this vulnerable stage and identify how donation can alleviate their emotional upheavals can facilitate their consent to the donation (234-236). This 
approach recognised the inter-connectedness of families, donors and donees, their roles in organ donation, and the importance of "seeing” from the families' viewpoint. Similarly, when families contravened donor's prior expressed wish, it highlighted the difficulties donors faced in anticipating the effects of their choices on their families and whether they would have maintained their decisions to donate with unintended effect/“harm” on their families (236, 240). This compels us to consider the extent to which healthcare teams can support the families as they journey through the donation process, which then provides a framework in determining tailored, good care to the families. The next section explores the ways in which care ethics can apply throughout the three phases of organ donation. For ease of discussion of and reference to the various stakeholders in the organ donation journey, the inclusive set of donor-family-healthcare provider-transplant team-donee stakeholder is known as "DonorsTransplant” stakeholder where appropriate. "Donors” encompass organ donors, families and healthcare providers, while "Transplant” comprises organ procurement specialists, requestors, transplant surgeons and donees. While each plays distinct roles with competing interests, each functions to support and maintain organ donation decision-making that respects crucially relevant conflict-of-interest considerations.

\section{The Donors-Transplant Paradigm: Care in the Donation Journey}

\section{Care prior to requests for donations}

How well does the organ donation system equip people as participants, rather than as objects, with organs to be harvested? An important aspect in the beginning of the donation process is the opportunity to engage with the concept, the processes and the effect upon the donors, their families and beyond before such requests are made. Care ethics imply that this feature of the relationship between the Donors-Transplant stakeholders in the organ donation process merit reconsideration. Organ donation campaigns are often aimed at encouraging 
people to donate, because it is seen as laudable and that people should be proud to engage in such altruistic actions. This approach neglected the donor's preferences regarding donation, and appeared to outweigh the interests of potential donees. People may refuse to donate on various grounds, ranging from distrust in the transplant system or perceptions of donee justifiability in receiving organs (Morgan et al 2008; Sommerville 2003) or out of fear for family repercussions (Walker et al 2013, 1348, 1349). Where donors have expressed the intention to donate, they should be informed about the medical conditions and the manner and stages of death that would make the organs viable for transplant (Sque et al 2018). Further, it necessitates an appreciation of brain death and treatment withdrawal issues. Care is demonstrated through caring for their needs to understand these important issues, and recognising their right to access this information. Farsides (2012) rightly reframed the consent process in organ donation that removes doubts regarding the donor's decision:

[T]he more that individuals witness the reality of post-mortem donation first hand or through the accounts of significant others, the more they will understand and accommodate the range of possible procedures entailed. In turn, doctors will be able to trust that someone, who has expressed a wish to donate, does so on the basis of a reasonable background understanding combined with the level of information they wished to receive. By sharing stories of donation, we can share the facts relating to procedures and the facts about the wish that has been fulfilled. Thus, the sharing of stories will inform those who wish to be informed, while still emphasizing the goal-oriented and wish-fulfilling nature of the interventions involved. (i77)

The timing, space and circumstances of providing organ donation information are equally essential. Key information are often communicated at critical points when decisions regarding donations are required, so that families, faced with the shock of the possibility of death of their loved ones are inclined to refuse such requests. Policy makers and the healthcare teams play vital roles in communicating the complexities of the donation process so that people can appreciate the nature and consequences of donation before requests are 
made, such as information on who, what, where, when and how of donating to clarify their doubts (Murphy and Smith 2012, i60). Specialist organ procurement coordinators, including requestors are valuable in providing both instrumental (e.g. physical comfort or acting as communication links between doctors and families) and emotional (e.g. expressing empathy and unreserved support regardless of donation decisions) support to prospective donor families where requests for organs were made (Anker, Akey and Feeley 2013). All these point towards constructing a caring climate and secure environment for donor families as they journey through the donation decision-making process.

Education, including school-based and at population levels, is instrumental in dispelling organ donation myths, and especially important when carried out in nonemergency conditions (Waldrop et al 2004; Morgan and Miller 2002; Chouhan and Draper 2003). This would be similar to blood donation campaigns or advance care planning for future incapacity promotional activities. Some advocates suggested harnessing social media to normalise these conversations and spread awareness to pre-empt pain and donation apprehensions (Sadler and Sadler 2015). Family support and participation from the clinical teams in donation conversations have been shown to correlate with the person's preference to donate and vice versa (Morgan et al 2008; Sommerville 2003). These conversations often require family members' involvement to promote greater understanding of the transplant process while mediating the strains arising from the process. An inadequate comprehension regarding organ donation processes is a strain factor, thus necessitating continuing information to families after consent is given (Berntzen and Bjork 2014). It also signifies to the donors and their families that their gifts of organ is valued, through active actions that seek to properly inform them of the process. 
Engaging in organ donation conversations promotes care with implications from two perspectives: for the donor before the decision is made or in the process of contemplating to donate; and the family's decision to accept or refuse when the donation request is made. For the donor, it ensures that they have understood what the donation entails and the processes, while for the families when they are better informed about the donor's decision. This approach would feed forward to the second phase where tensions often occur in refusals to donate. Such conversations should be recorded and any objections noted. The process of consenting itself, as Farsides (2012; 2011, 222, 223) has indicated, is a linchpin to the consent issue in organ donation.

Spain has often been hailed as one of the finest examples of successful organ transplant model (Rios et al 2018; Manyalich et al 2011). Beneath this structure we find the dynamics of human interactions and synergies between the donors' families and healthcare teams, allowing care integration. The Spanish organ transplant system reveals a systematic structure that enables defined transitions from managing waiting lists, transferring organs to training healthcare and transplant teams and promoting public awareness (Gilligan et al 2012) and improving ways of approaching and caring for families (Matesanz et al 2011; Arias et al 2010; Blok et al 1999). Well-trained transplant teams have successfully made transplant possible through reducing the tensions that occurred in the process of procuring organs, thus creating an effective organ donation environment (Manyalich et al 2011). One of the key features of its successful approach is the high level of trust by the Spanish population in their healthcare system, demonstrating elements of reciprocity in the state-population relationship, where they know that everyone gets a fair chance, within efficient resource management systems in organ allocations. The higher the assurance of accountability and clarity of the organ donation processes, the more likely are people to engage with donations. Studies have demonstrated that British citizens residing in Spain are more likely than their British 
counterparts in Britain to donate (de Lago 2011; Rios et al 2008; Rios et al 2007), in addition to knowledge of religious approvals towards organ donations (Rios et al 2015; Rios et al 2010). Their media campaigns, for example, demonstrated active steps in informing the public, ranging from 24 hours transplant hotlines, to meetings between public figures and representatives from the media, and training in communication to ensure people are aware of what is involved in the process (Matesanz 2003, 737). The Spanish perspective implicitly recognised the importance of human interactions in the moments leading to actual transplants, focusing on training emphatic communication with the family, being attentive to their needs, creating appropriate space for informing them about death and donation, negotiating the time and ways to request for organs, and dealing with refusals to donate so that they do not resent their decisions resulting in regret or guilt. By ensuring that everyone is cared for and acknowledging the relationships between the parties in this momentous decision, it eases the path towards accepting organ donation as part of routine end-of-life decisions.

It is clear that there exists information asymmetry within the current framework based on justice and utilitarian presumed consent, with the effect that legislators create opportunities and support actions that are inclined towards promoting organ donation. This seems to be contrary to the gift-of-life premise underpinning organ donation, as such asymmetry is inadvertently disguised under the cloak of altruism. Consequently, it produces information that is biased towards the benefits of donating. Being informed patients, as bioethical principles reminded us, means that healthcare providers have the duty to inform people about the nature of organ donation. The inadequate disclosure regarding organ donation processes would mean that people are unable to genuinely decide based on the existing, limited range of information. At the other end of the spectrum, some may not wish 
to engage in organ donation, and needs to be respected. It is likewise possible within the spectrum where people decide to donate regardless of the information available out of altruism. Nevertheless, the transplant system is a web of complicated algorithm, the extent to which people are aware of the intricate workings is questionable, as it potentially affects their attitudes to donate. Social attitudes are essential because an organ donation system is an interdependent activity involving clinical-ethical, technical, and physical coordination, and individual willingness in the society (Manyalich et al 2011). Care ethics demand that this information asymmetry and donation predispositions be rectified. The aim of organ donation is broadly geared towards human flourishing, extending beyond non-maleficence to beneficence towards self and others within a framework that emphasised both relationships and responsibilities. When we acknowledge the universal need for care and compassion, we would be mindful towards the donor and their families' needs, and know when and how to meet those needs to promote their wellbeing. Caring for information symmetry thus obliges us to respect donor and their families' autonomy, as without such attitudes, donors are reduced to conduits for organs.

\section{Bereavement, grief and second life: care during donation process}

The decision to donate often affects the living and families play decisive roles in realising donation in an emotionally challenging environment (Sque and Sutehall 2011). In the European context, Walker and colleagues' (2013) reviews on family perspectives in organ donation and the factors influencing their donation decisions highlighted that families often reacted to their emotions through expressing recovery hopes, denial, anger and prolonging decision-making time (1348, 1349). Families were also concerned about the efficacy of extracting organs that might be unsuitable after transplant, or served as "standby” (ibid). The fact that they have little control over their response to the loss means that they would find it 
difficult to engage meaningfully in donation requests which can be mediated by building good relationships with the families so that they can appreciate that they and the dead donors are actually being cared for (Sque and Sutehall 2011, 72).

Organ donation is distinct from other surgical procedures, because it involves gratitude, grief, happiness and equity (Sanner 2003). It exemplifies the essence of the relational nature, and human interlinking situated within care ethics. Comprehending the ethical relationship between the deceased and the families sheds light towards understanding the reasons for their refusal (Haddow 2005; Sque et al 2014). Families responded favourably to facilitators who are sensitive, kind, calm and gentle when requests for donations were made (Sque et al 2018). Being thoughtful of how families interact with others and respond to the situation enables a tailored approach to care for the families, who may vacillate between “emotion-focused” and “problem-focused” coping mechanisms (Sque and Sutehall 2011, 72, 73). Families' attitudes towards death, and the strength and continuity of relationships with the deceased influenced their donation decisions (Haddow 2005). Families need reassurance that medical care would remain uncompromised once donation decisions are made; suggesting that an ethical climate that emphasised patient-doctor relationship, overcoming ethical conflicts and promoting greater acceptance from donor-family and clinical team is important (Quinn et al 2013).

Empathy in doctors-family communication has been recognised as positively influencing families' consent to donate (Bocci et al 2016; Jacoby et al 2006). Empathy exemplifies caring characteristics such as understanding the donor family's socio-cultural background, listening to families narrating memories of the donor, welcoming the families kindly, involving specialists from various backgrounds to offer guidance and support to 
counter feelings of vulnerability and anxiety and enabling spaces for expressing frustrations or denials (Bocci et al 2016). Broaching the requests for donation is thorny, but a private, caring atmosphere facilitated by skilled and experienced people could mediate difficult emotional responses (3248). As such, these facilitators would need to reach out to the families through expressions showing that they share their sentiments and evoke feelings of togetherness as they go through this process. Despite the significance of empathy among healthcare professionals, this attribute became progressively eroded in medical students as they advanced in their studies (Holmes et al 2017; Burks and Kobus 2012; Smajdor et al 2011), resulting in deficiency in patient care. Consequently, continuous professional training is essential, particularly in consultation communications and other "soft skills" in the medical curriculum (Smajdor et al 2011). Recommendations to promote empathetic skills include mindfulness training and self reflection, supported by realistic daily practices in the doctors' values and interactions (Burks and Kobus 2012). After all, empathy connects shared human experiences and is especially valuable in organ donations that embody altruistic ideals and social benefit tensions.

Treating donors with dignity and respect are coping mechanisms that eases their pain. Thus, itemising organs for donations upsets families, as it illustrates their perceptions of dignity and concerns with protecting the physical body of the dead donor from "violation" via organ extraction (87). The time intervals in requesting for donations affect the willingness to donate (Rogers et al 2011), demonstrating tensions between preserving organ viability and accommodating families' time with the deceased. An Australian study showed that less than half of the respondents chose a timeframe within organ viability, thereby potentially compromising successful transplants (583). Recognising these aspects lend weight to the quality of care donor families receive. The emotional toll on doctors who are engaged in the organ donation journey may lead some to hesitate in approaching bereaved families out of 
compassion and respect, thus highlighting the ethical dilemma of caring for organ donors (Walker and Sque 2016; Kjell et al 2015). Some doctors do not treat donors differently from other patients receiving treatments, enabling doctors to reframe the meaning of life through the act of donating and life changing benefits to future donees (Sadala et al 2006, 194). This approach towards care comports with the Kantian dictum of never treating humans as a means to an end (Kjell et al 2015, 170). Doctors and families are bound by the tragedy of the donors' death, offering the impetus to create a new "community" shared by the donation journey (Bocci et al 2016, 3245). This aspect of community will become important when I discuss post-donation care in the next section.

We can see that there is more progress in research leading to developing caring practices for bereaved families compared to the pre-donation aspect. Care here illustrates how families are prioritised and involved in the process at each step. They show active interventions in considering how, when and where requests for organs should be made, in balancing competing interests towards actualising the transplant while offering the chance for a second life to future donees and accommodating families' needs for reassurance and grief. The common theme is that caring actions emphasised on training for healthcare teams to more appropriately respond to families' needs for caring support at this difficult time. The Donor-Transplant stakeholders are engaged in a shared emotion journey in honouring the donor's wishes, while acknowledging the moral distress on both sides affecting the doctorpatient relationships and caring for the living as they process their grief. Appreciating the spectrums in which emotions can fluctuate can offer insights into the decision-making process and tailor the best approach to accommodate each step in the journey. As NavarroMichel (2011) accurately observed, doctors respecting the family's wishes regardless of their decision ultimately engender trust, and circumvent conflict which has a spill-over effect on the transplant system. 


\section{Follow up care post donation}

It is imperative that donor families are appreciated as having significantly contributed towards furthering the donors' intentions. This may likely contribute to their desires to connect with the donees post donation or for refusing certain organs for donations due to particular attachments and symbolic meanings attributed to the deceased. Research suggested that quality follow-up is beneficial for donor families in enhancing their understanding, recognition and reconciliation (Sque et al 2018, 88). The good relationship between the transplant coordinators and families potentially lasts beyond the donation decisions, affecting post-donation care and the wider community, benefiting the donation cycle in the long term (Anker, Akey and Feeley 2013, 842). Although it is accepted that good care provision are offered for organ donors and their families once donors are identified, systematic practices of care and communication in the post-donation period appeared patchy, with an absence of proactive continuity in the care within the organ donation cycle.

Families experienced enduring effect after the deceased's death post donation. Relatives who consented to or declined donations of brain dead relatives suffered posttraumatic stress disorder after the deceased's death, which are heightened in situations of indecisive donation decisions and professionals' lack of person-focused behaviour (Kesselring, Kainz and Kiss, 2007, 215, 216). This indicates the need for psychological support beyond standard information provision, while being fully attentive and compassionately listening to avoid additional harm arising from the request. Manzari and colleagues (2012) accurately observed the oversight of psychological impact of organ donations on donors' families as issues are often framed in consent $(654,655)$. Crucially, any unanswered questions regarding the donation process, and brain death prognosis were identified as difficult emotional experiences for families to process, which led to feelings of 
remorse and anxiety (663). A Korean hospital-based organ procurement organisation which investigated donor families' emotions post donation shared several similar findings to the study above despite socio-cultural variance (Kim, Yoo and Cho 2014). The authors concluded that families experienced mixed emotions, and required continuous and consistent support to encourage their psychological stability (3256). Administrative procedures following death is cited as distressing, while religious practices, "support from funeral related experts... and spending time with family and friends” offered psychological relief post donation (3256). However, post donation follow-up care through telephone calls and letters to donor families offered little relief for them (ibid). The authors recommended "systematic intervention like self-help meetings for donors' families as well as family bereavement programs” and a culturally responsive national cooperative measure (ibid).

Thus far I have referred to families as a unit collectively, however within this unit it is often easy to overlook the conflict existing between each member who may be involved in the decision-making process. Caring is vital to ensure that dissenting members are equally cared for, as without this consideration, it is likely to influence the healing process postdonation and affect their own decisions when it is their turn to make these donation decisions. Earlier I have indicated the need for space for families to deal with the grieving and process their decision-making thoughts when requests for donations are made. It becomes vital to be attuned to these potential conflicts and to expertly care for the dissenting members. Specialists need to mediate the situation, support, comfort, diffuse the tensions before it escalates, and create a sense of community, acknowledging that the decision is life-changing for the living. Care encompassed both physical and psychological care (trust, respect, involvement); traits that signalled reciprocal caring relationships between families, healthcare and transplant teams (Walker et al 2013, 1352; Adanir et al 2014; Fernandes et al 2015). 
These factors reinforced the significance of care throughout the donation journey that translates to post donation phase:

The dimensions of past, present, and future captured the affective nature of decision-making about organ donation by firmly placing the study findings in the context of the family's temporal landscape...Perpetual deficits in care and communication that negatively affect bereaved families' decisions about organ donation suggest room for improvements in clinical care. Supporting family members in their grief by facilitating understanding and acceptance of death appeared instrumental in enabling the bereaved to consider future perspectives (Walker et al 2013, 1353, 1355).

While post donation care is important, actions to support this area are under-explored, highlighting the necessity of establishing actions to improve the past-present-future paradigm of organ donations. Continuing to strengthen ties with families post donation is essential (Fernandes et al 2015, 899). Addressing family struggles with their internal conscience and conflicting emotions is particularly acute where donor death is sudden and traumatic. Kim and colleagues' proposal for a systematic follow-up care merits serious consideration, for it illustrates active interventions for the continuity of care for donor families, further inculcating a sense of community in the cyclical donation environment. While people often hoped for successful post donation transplants, surgical risks may result in failed transplants. Postdonation caring would include informing families of transplant outcomes, unless families declined to be informed. Successful transplants help families see the contributions the deceased have made, while failed procedures might inadvertently amplify the loss. Despite accepting the donation attempts, families and donees experienced trauma arising from failed donations in terms of organ wastage, confronting a "second loss”, failure to honour donor's intentions and difficulty in the grieving process (Taylor et al 2018). Frank disclosures regarding the transplant outcomes demonstrate accountability to the donor's intention and 
transparency for the families, consistent with the dimensions of how organ donation affects the past, present and future of families coping with the outcomes. The possibilities of successful or failed transplant outcomes should be included in the initial discussion between donors and their families in the pre-donation cycle, so that families are prepared for this eventuality. Additionally, post donation care is valuable in supporting families who regretted their decisions to override the deceased's decision to be an organ donor. The decision to donate is, on the surface, a personal decision which is meaningful to the donor, yet we have seen the interlinking relationships within the Donor-Transplant paradigm. Caring for families who have regrets means uncovering the reasons for their decisions to veto and supporting them in understanding and accepting the donors' decisions while processing their feelings.

\section{Implications for law and clinical practice}

What practices need to change, or liable for improvement in each of the stages? The law has the potential to influence population behaviour; as research has shown that the extent to which families participate in organ donation decision-making is largely shaped by the processes instituted according to the countries (Walker et al 2013, 1340). Evidence from empirical studies discussed above offered insights into what has been implemented and could be advanced for future roadmap. The pre-donation phase offers a timely opportunity to reframe the approach towards organ donation. The law should mandate that a transparent and accountable educational and awareness activities underpinned by care are undertaken to remedy the information asymmetry identified in the process. This approach seeks to engender the population trust in the donation system and create an ethical climate for organ donation to thrive. 
Raising awareness does not simply mean asking people to become organ donors. It should present genuine facts and clarify any doubts surrounding the process and actively facilitate open conversations about organ donations. The way they are communicated to the public merit careful contemplation in striking a balance between building public trust (involving donors, their families, healthcare providers and the transplant teams) and caring for future donees whose life depend on organ availability. Research has recognised the difficulty with communicating the clinical distinctions between life and death concerning donations after brain death and circulatory death to the public, especially where competing interests are involved (Taylor et al 2018). It is possible to extend the scope of the legal obligation to inform to organ donation, particularly; answering important questions pertaining to what happens when death occurs, the use and timing of organs extracted from the body, or post donation matters. These questions may, at first blush, seem elementary yet they are frequently asked by donor families and overlooked by donors. As Farsides has highlighted, the failure to provide the option to refuse organ donation in UK drivers licence raises ethical concerns. This absence, in effect, pushed the decision-making to families in the next phase where critical decisions are made under intense psychological strains. It may be necessary to develop separate legal processes to obtain the informed consent of relatives who are appointed as substitute decision-makers in resolving remaining questions neglected by donors.

Normalising the culture of engaging in organ donation conversations includes understanding the potential challenges surrounding end-of-life care and how they are associated with organ donation. The UK framework is based on the belief that organ donation "should be viewed as part of end-of-life care” (Murphy and Smith 2012), which entails integrating organ donation conversations into longer term advance care planning (ACP) conversations (Haesen and Shaw 2018; Matesanz et al 2017, 1451). ACP generally provides 
the opportunity for people to express their treatment preferences that would apply in times of future incapacity according to their beliefs and values. ACPs are not restricted to medical treatment options, and could contain wishes for hospice or home care, funeral plans and designating substitute decision-makers. An advantage in incorporating organ donation conversations into ACP is that ACP activities are already promoted to the population. Conversations that take place in ACP can help towards answering questions regarding the level of care provided to them, clarifying the donation process, criteria and eligibility in the legal and clinical framework, identifying potential barriers to donate and tailoring the level of care for the family. The valuable space to engage in these conversations in a least difficult time can optimise the chances of reaching informed decisions in a supportive setting. Although a favourable decision to donate is not a given, it offers a platform for people to think about their preferences in a non-emergency setting, and encourage donors to inform their families about their decisions. This approach can accommodate a highly personal and culturally nuanced discussion of organ donation. It is likewise essential to advise people that the ACP can be reviewed to reflect the changing preferences as the time goes by, for example, what would be important to younger people would differ from older people in terms of preferences to donate organs. A further potential is addressing concerns regarding low participation rates from ethnic minorities in organ donation. Simply highlighting that particular ethnic groups as representing the lowest pool of organ donors smacked of a generalist, non-caring attitude that everyone should become organ donors. Instead, it is essential to understand distinctive funeral practices or religious beliefs that affect their attitudes towards organ donation.

Implementing systematic post donation follow-up care is closely connected to the second phase of critical donation requests. One of the focus points emerging from this aspect is the restorative effect post-donation care has on donor families and the donee. Grieving 
families need ongoing professional support to cope with the loss and providing follow-up care is essential in maintaining their psychological health. People cope with loss differently and having tailored support would invariably reduce the time taken to mourn and translate into a more positive experience where there is less guilt or anxiety about their donation decisions. Hospitals or organ procurement units can offer the space and create support groups for families with experience consenting to or refusing organ donations to share their stories, as mutual support while coping with bereavement simultaneously. This network would also act as resources for potential donors and their families to learn about the process and hear their first-hand accounts of what it is like to be in that situation to foster their mental preparedness and future wellbeing post donation.

Another option is establishing a confidential, secure donor family-donee registry for those who wish to keep in touch with each other. This option should be entirely voluntary because some would be uncomfortable to engage with others, but this opportunity would be valuable for those who have expressed the desire to see their "contributions" to the donees and where donees have the mutual wish to connect with the donor families. Such registries could comprise of one which record objections by families and the other that note refusals by donors. The latter would ensure that donors know that families can object after their death, which in turn compel them to consider the consequences and effect on their families and whether they still intended it. It could be introduced at the point of signing up as organ donors to encourage open conversations between donors and their families. This option facilitates donors to inform their families, with the likelihood that they would be less inclined to object if they knew that this was what the donors wanted and for the wishes to be respected. This should be managed by a Committee or under the auspices of a ministry or a special task force. It would have the benefit of creating a truly caring ethical climate for organ donation 
because it corresponds with the essence of organ donation - to enable a second life to numerous donees.

\section{CONCLUSION}

This article has sought to articulate the application of care ethics to address the organ donation challenge in respect of family refusals through the three phases of donation. A close examination of the ethical climate reveals the importance of underpinning the organ donation framework on care ethics, offering an alternative to the fragmentary approach to existing concerns. A care ethics is appropriate for organ donation because it engages with the difficult and sensitive issues arising from human interactions in the donation journey. Care ethics encompasses the characteristics that best promote human wellbeing; the donor's expressed wishes to donate, donor-families' attachment to the donor beginning from consenting to donate, to dealing with the grief and post donation that demonstrates respect for their autonomy and dignity.

While numerous proposals have been advocated to address the organ shortage challenge, they overlooked the interrelated nature of the donation journey and the intricacies surrounding competing interests within the Donor-Transplant dimension. Considerable tensions arise in implementing donations based on presumed consent, and studies have revealed inconclusive evidence regarding the effectiveness of the model in increasing donor pool. One of the key challenges is encouraging families to agree with donation decisions, which demonstrates the centrality of the role of families in donation decision-making. Research has shown that caring for families translates into a more genuine decision to donate 
which has less negative repercussions long after the donation decision is made, compared to a less-caring environment. Caring for families enables the greater chances of the donor wishes being respected, while recognising families' active engagement with the decision in times of distress, and balancing the interests of donees. Organ donation comprises questions of equity, beliefs, values and subjective attitudes of each stakeholder in the process; accordingly, being mindful of the underlying causes influencing the decision-making is a step towards recognising the myriad of values that influence the process and how applying a caremotivated approach can resolve some of the difficulties in the donation process.

(8,632 words)

\section{References}

A strategy for delivering a revolution in public behaviour in relation to organ donation 23red for NHS Blood \& Transplant March 2014.

Abouna GM.2008. Organ shortage crisis: problems and possible solutions. Transplant Proc. 40(1):34-38.

Adanir, T,I. Erdogan, G. Hunerli, G. Unveren, H. Dasci, H.Y. Cetin, I. Ozsan, and U. Aydin. 2014. The Effect of Psychological Support for the Relatives of Intensive Care Unit Patients on Cadaveric Organ Donation Rate. Transplantation Proceedings 46: 3249-3252.

Albertsen, Andreas. 2018. Deemed consent: assessing the new opt-out approach to organ procurement in Wales. J Med Ethics44:314-318.

Anker, Ashley E, Jessica E. Akey and Thomas Hugh Feeley. 2013. Providing Social Support in a Persuasive Context: Forms of Social Support Reported by Organ Procurement Coordinators. Health Communication 28(8): 835-845.

Arnaud, Anke, and Marshall Schminke. 2012. The Ethical Climate and Context of Organizations: A Comprehensive Model Organization. Science 23(6):1767-1780. 
Bartholdson, Cecilia, Margareta af Sandeberg, Kim Lutzén, Klas Blomgren and Pernilla Pergert. 2016. Healthcare professionals' perceptions of the ethical climate in paediatric cancer care. Nursing Ethics 23(8): 877-888.

Berntzen, Helene and Ida Torunn Bjørk. 2014. Experiences of donor families after consenting to organ donation: A qualitative study. Intensive and Critical Care Nursing30: 266-274.

Bilgel, Firat. 2013. The effectiveness of transplant legislation, procedures and management: Cross-country evidence. Health Policy 110: 229-242.

Blok GA, J, van Dalen, KJ, Jager, M, Ryan, RM, Wijnen, C, Wight, JM, Morton, M, Morley and B, Cohen. 1999. Transpl Int 12(3):161-167.

Bocci, M.G, C. D’Alò, R. Barelli, S. Inguscio, A. Prestifilippo, S. Di Paolo, S. Lochi, M. Fanfarillo, D.L. Grieco, R. Maviglia, A. Caricato, G. Mistraletti, S. Pulitanò, M. Antonelli, and C. Sandroni. 2016. Taking Care of Relationships in the Intensive Care Unit: Positive Impact on Family Consent for Organ Donation. Transplantation Proceedings 48: 3245-3250.

Bulcke B, Van den, Piers R, Jensen HI, et al. 2018. Ethical decision-making climate in the ICU: theoretical framework and validation of a self-assessment tool. $B M J$ QualSaf doi: 10.1136/bmjqs-2017-007390.

Burks, Derek J and Amy M Kobus. 2012. The legacy of altruism in health care: the promotion of empathy, prosociality and humanism. Medical Education 46: 317-325.

Caplan, Arthur. 2016. Finding a solution to the organ shortage. CMAJ 188(16):1182-1183.

Chouhan P, and H. Draper.2003. Modified Mandated Choice for Organ Procurement. J Med Ethics 29(3):157-162.

Cloconi, Constantina, Evridiki Papastavrou and Andreas Charalambous. 2018. Cancer nurses’ perceptions of ethical climate in Greece and Cyprus. Nursing Ethics 1-17. 
Coppen, Remco, Roland D. Friele, Jouke van der Zee, and Sjef K. Gevers.2010. The potential of legislation on organ donation to increase the supply of donor organs. Health Policy 98: 164-170.

Cronin, Antonia J, and John Harris. 2010. Authorisation, altruism and compulsion in the organ donation debate. J Med Ethics 36(10):627-631.

de Casterle', Bernadette Dierckx, Sofie TL Verhaeghe, Marijke C Kars, Annemarie Coolbrandt, Marleen Stevens, Maaike Stubbe, Nathalie Deweirdt, Jeroen Vincke, and Maria Grypdonck.2011. Researching lived experience in health care: Significance for care ethics. Nursing Ethics 18(2): 232-242.

English, V, and A Sommerville. 2003. Presumed consent for transplantation: a dead issue after Alder Hey? J Med Ethics 29:147-152.

Farsides, Bobbie. 2012. Respecting wishes and avoiding conflict: understanding the ethical basis for organ donation and retrieval. British Journal of Anaesthesia 108 (S1): i73-i79.

Farsides, Bobbie. 2011. Negotiating Change: Organ Donation in the United Kingdom. In Organ Shortage: Ethics, Law and Pragmatism, eds. Anne-Maree Farrell, David Price and Muireann Quigley, 215-226. Cambridge, UK: Cambridge University Press.

Fernandes, Marli Elisa Nascimento, Zélia Zilda Lourenço de Camargo Bittencourt, and Ilka de Fátima Santana Ferreira Boin. 2015. Experiencing organ donation: feelings of relatives after consent. Rev. Latino-Am. Enfermagem 23(5):895-901.

Forsberg, Anna, Anne Flodén, Annette Lennerling, Veronika Karlsson, Madeleine Nilssong, and Isabell Fridhe. 2014. The core of after death care in relation to organ donation - A grounded theory study. Intensive and Critical Care Nursing 30:275-282.

Gilligan, Carol.1982, 1993. In a Different Voice: Psychological Theory and Women's Development. Cambridge Massachusetts, USA and London, England: Harvard University Press. 
Gilligan, Conor, Robert William, Sanson Fisher, and Heidi Turon. 2012. The organ donation conundrum. Progress in Transplantation 22:312-316.

Groot, Jack de, Maria van Hoek, Cornelia Hoedemaekers, Andries Hoitsma, Wim Smeets, Myrra Vernooij-Dassen and Evert van Leeuwen. 2015. Decision making on organ donation: the dilemmas of relatives of potential brain dead donors. BMC Medical Ethics16:64.

Guttman, Nurit, Gil Siegal, Naama Appel, and Gitit Bar-On. 2016. Should Altruism, Solidarity, or Reciprocity be used as Prosocial Appeals? Contrasting Conceptions of Members of the General Public and Medical Professionals Regarding Promoting Organ Donation. Journal of Communication 66: 909-936.

Haddow, Gillian. 2005. Death, embodiment and organ transplantation: The phenomenology of death, embodiment and organ transplantation. Sociology of Health \& Illness 27(1):92-113.

Haesen, Sophie and David Shaw.2018. doi:10.4414/smw.2018.14628 Directing citizens to create advance directives. Swiss Med Wkly148:w124628.

Hawkes, Nigel. 2018. "Muddy waters" surround evidence for opt-out system of organ donation, says surgeon. BMJ 360:k744 doi: 10.1136/bmj.k744

Held, Virginia. 2006. The Ethics of Care: Personal, Political and Global. New York: OUP.

Henderson, Macey L. and Jed Adam. 2017. Gross Living Organ Donation and Informed Consent in the United States: Strategies to Improve the Process. The Journal of Law, Medicine \& Ethics 45: 66-76.

Hobday, Mike. 2015. Time to debate an opt-out system for organ donation in England as well as the rest of the UK. BMJ 351:h6140 doi: 10.1136/bmj.h6140

Holmes, Cheryl L, Harry Miller and Glenn Regehr. 2017. (Almost) forgetting to care: an unanticipated source of empathy loss in clerkship. Medical Education 51:732-739. 
Hulme, W, J. Allen, A. R. Manara, P. G. Murphy, D. Gardiner and E. Poppitt. 2016. Factors influencing the family consent rate for organ donation in the UK. Anaesthesia 71:1053-1063.

Isch, D. J. 2007. In defense of the reverence of all life: Heideggerean dissolution of the ethical challenges of organ donation after circulatory determination of death. Medicine, Health Care and Philosophy 10:441-459.

Jacoby, Liva, Vicki Crosier, and Henry Pohl.2006. Providing support to families considering the option of organ donation: an innovative training method. Progress in Transplantation $16: 247-252$.

Kesselring, A, M. Kainz and Alexander Kiss.2007. Traumatic Memories of Relatives Regarding Brain Death, Request for Organ Donation and Interactions with Professionals in the ICU. American Journal of Transplantation 7: 211-217.

Kim, H.S, Y.S. Yoo and O.H. 2014. Cho Satisfaction with the Organ Donation Process of Brain Dead Donors’ Families in Korea. Transplantation Proceedings 46:3253-3256.

Kjell, AudOrøy, Erik Strømskag, and Eva Gjengedal. 2015. Do we treat individuals as patients or as potential donors? A phenomenological study of healthcare professionals' experiences. Nursing Ethics22(2): 163-175.

Koskenvuori, Janika, Olivia Numminen and Riitta Suhonen. 2017. Ethical climate in nursing environment: A scoping review. Nursing Ethics 1-19.

Kuhse, Helga.1997. Caring: Nurses, Women and Ethics. Oxford, UK: Blackwell Publishers.

Kuntz, J. R. C, J. R. Kuntz, Detelin Elenkov, and Anna Nabirukhina. 2013. Characterizing Ethical Cases: A Cross-Cultural Investigation of Individual Differences, Organisational Climate, and Leadership on Ethical Decision-Making. J Bus Ethics113:317-331.

Lago, María de. 2011. Organ donation rates in Spain for British residents are higher than in UK.BMJ343:d4948 doi:10.1136/bmj.d4948 
Lamiani, Giulia, Lidia Borghi and Piergiorgio Argentero. 2017. When healthcare professionals cannot do the right thing: A systematic review of moral distress and its correlates. Journal of Health Psychology 22(1):51-67.

Levitt, Mairi. 2015. Could the organ shortage ever be met? Life Sci Soc Policy 11:6.doi: $10.1186 / s 40504-015-0023-1$

Lin, Yen-Ko, Wei-Che Lee, Liang-Chi Kuo, Yuan-Chia Cheng, Chia-Ju Lin, Hsing-Lin Lin, Chao-Wen Chen and Tsung-Ying Lin. 2013. Building an ethical environment improves patient privacy and satisfaction in the crowded emergency department: a quasi-experimental study. BMC Medical Ethics 14:8 doi:10.1186/1472-6939-14-8.

Manyalich, Martı́, Carlos A Mestres, Chloe Balleste', Gloria Pa'ez, Ricard Valero and Marı́a Paula Gómez. 2011. Organ procurement: Spanish transplant procurement management. Asian Cardiovascular \& Thoracic Annals 19(3/4): 268-278.

Manzari, Zahra Sadat, Eesa Mohammadi, Abbas Heydari, Hamid Reza Aghamohammadian Sharbaf, Mohammad Jafar Modabber Azizi and Ebrahim Khaleghi.2012. Exploring families’ experiences of an organ donation request after brain death. Nursing Ethics 19(5): 654-665.

Martin, Kelly D, and John B. Cullen.2006. Continuities and Extensions of Ethical Climate Theory: A Meta-Analytic Review. Journal of Business Ethics 69:175-194.

Martinsen, Elin. 2011. Harm in the absence of care: Towards a medical ethics that cares. Nursing Ethics 18(2): 174-183.

Matesanz, R, B. Domınguez-Gil, E. Coll, B. Mahıllo and R. Marazuela. 2017. How Spain Reached 40 Deceased Organ Donors per Million Population. American Journal of Transplantation 17:1447-1454.

Matesanz, R. 2003. Factors influencing the adaptation of the Spanish Model of organ donation. Transpl Int 16: 736-741. 
Matesanz, Rafael, Beatriz Domı́nguez-Gil, Elisabeth Coll, Gloria de la Rosa and Rosario Marazuela. 2011. Spanish experience as a leading country: what kind of measures were taken? Transplant International 24: 333-343.

McCartney, Margaret. 2017. When organ donation isn't a donation. BMJ 356:j1028.doi: 10.1136/bmj.j1028

M'hamdi, Hafez Ismaili, Medard Hilhorst, Eric A P Steegers, and Inez de Beaufort. 2017. Nudge me, help my baby: on other-regarding nudges. J Med Ethics 43(10): 702-706.

Morgan, Susan E, and Jenny K. Miller. 2002. Beyond the Organ Donor Card: The Effect of Knowledge, Attitudes, and Values on Willingness to Communicate About Organ Donation to Family Members. Health Communication 14(1): 121-134.

Morgan, Susan E,Tyler R. Harrison, Walid A. Afifi, Shawn D. Long and Michael T. Stephenson. 2008. In Their Own Words: The Reasons Why People Will (Not) Sign an Organ Donor Card. Health Communication 23(1): 23-33.

Murphy P. G, and M. Smith.2012. Towards a framework for organ donation in the UK. British Journal of Anaesthesia 108(S1): i56-i67.

Navarro-Michel, Monica.2011. Institutional organization and transplanting the 'Spanish Model'.In Organ Shortage: Ethics, Law and Pragmatism, eds. Anne-Maree Farrell, David Price and Muireann Quigley, 151-170. Cambridge, UK: Cambridge University Press.

Noddings, Nel. 1984. Caring: A Feminine Approach to Ethics \& Moral Education. Berkeley, LA: University of California Press.

Noyes J, McLaughlin L, Morgan K, et al. 2019. Short-term impact of introducing a soft optout organ donation system in Wales: before and after study. BMJ Open 9:e025159. doi:10.1136/bmjopen-2018-025159

Nuffield Council on Bioethics http://nuffieldbioethics.org/news/2018/nuffield-councilbioethics-raises-concern-lack-evidence-support $(23$ February 2018); 
http://nuffieldbioethics.org/news/2018/response-governments-plans-optout-system-organdonation (6 August 2018)

Numminen, Olivia, Helena Leino-Kilpi, Hannu Isoaho, and Riitta Meretoja. 2015. Ethical climate and nurse competence - newly graduated nurses' perceptions. Nursing Ethics 22(8):845-859.

P. Jordan Alexander. 2018. Welsh 2013 deemed consent legislation falls short of expectations. Health Policy https://doi.org/10.1016/j.healthpol.2018.07.019

Pettersen, Tove. 2011. The Ethics of Care: Normative Structures and Empirical Implications.Health Care Anal19:51-64.

Pillay, Prinitha. 2015. Resuscitating an ethical climate in the health system: The role of healthcare workers. South African Medical Journal 105(4):277-278.

Price, David. 2011. Promoting organ donation: challenges for the future. In Organ Shortage: Ethics, Law and Pragmatism, eds. Anne-Maree Farrell, David Price and Muireann Quigley, 245-268. Cambridge, UK: Cambridge University Press.

Quinn, Gwendolyn P, Devin Murphy, Christie Pratt, Teresita Muñoz-Antonia, Lucy Guerra, Matthew B. Schabath, Marino E. Leon, and Eric Haura. 2013. Altruism in terminal cancer patients and rapid tissue donation program: does the theory apply? Med Health Care and Philos16:857-864.

R'ios, Antonio, Laura Mart'ınez-Alarcon', Jose S'anchez ', Nick Jarvis, Jose A. Garcia, Jose M. Rodr'ıguez, Pascual Parrilla and Pablo Ram'ırez. 2008. The quest for favourable subgroups to encourage living kidney donation in Spain. An attitudinal study among British and Irish citizens resident in south eastern Spain. Nephrol Dial Transplant23: 1720-1727.

Rı́os, Antonio, Ana I. Lopez-Navas, Juan C. Navalon, Laura Martınez-Alarcon, Marco A. Ayala-Garcıa, Marıa J. Sebastian-Ruiz, Francisco Moya-Faz, Gregorio Garrido, Pablo Ramirez and Pascual Parrilla. 2015. The Latin American population in Spain and organ 
donation. Attitude toward deceased organ donation and organ donation rates. Transplant International 28: 437-447.

Ríos, A, A.I. López-Navas, Á. Sánchez, M.A. Ayala, G. Garridof , M.J. Sebastián, L. Martínez-Alarco, G. Ramis , A.M. Hernández, P. Ramírez, and P. Parrilla. 2018. Factors That Affect the Attitudes of the Bolivian Population in Spain With Regard to Organ Donation for Transplant. Transplantation Proceedings 50: 319-322.

Ríos, A, L. Martínez-Alarcón, J. Sánchez, A. López-Navas, G. Ramis, P. Ramírez, and P. Parrilla. 2010. Welsh Citizens in South-Eastern Spain: A Study of Attitude toward Organ Donation. Transplantation Proceedings 42: 3116 -3119.

Ríos, A, P. Cascales, L. Mart'inez , J. Sanchez , N. Jarvis , P. Parrilla and P. Raḿırez. 2007. Emigration from the British Isles to Southeastern Spain: A Study of Attitudes toward Organ Donation. American Journal of Transplantation 7: 2020-2030.

Rodríguez-Arias, David, Linda Wright, and David Paredes. 2010. Success factors and ethical challenges of the Spanish Model of organ donation. Lancet 376: 1109-1112.

Rogers, W. A, S. de Lacey and J. C. Avery. 2011. Donation after Cardiac Death: Community Views about 'Decent’ Intervals. American Journal of Transplantation 11: 583-590.

Roybal, Deb. 2017. What We Say, What They Hear: Perceptions of Organizational Values and Ethical Climate in the Health Care Setting. Nurse Leader 251-257.

Sadala, Maria Lúcia Araujo, Marisa Lorenc, Márcia Cercal and Arthur Schelp. 2006. Caring for organ donors: The intensive care unit physicians’ view. Heart \& Lung 35(3): 190-197.

Sadler, Blair L, and Nicole Robins Sadler.2015. Having Conversations about Organ Donation. The Hastings Center report. 09: 45(5) DOI: 10.1002/hast.485

Sander-Staudt, Maureen. Care Ethics (Internet Encyclopedia of Philosophy) <https://www.iep.utm.edu/care-eth/> accessed 10 April 2019. 
Sanner, Margareta A. 2003. Transplant recipients' conceptions of three key phenomena in transplantation: the organ donation, the organ donor, and the organ transplant. Clin Transplant 17: 391-400.

Saul, P.2012. Why isn't organ donation part of advance care planning? BMJ Supportive \& Palliative Care2:173.

Saunders, John. 2010. Bodies, organs and saving lives: the alternatives. Clinical Medicine 10(1): 26-29.

Sharif A, and Moorlock G. 2018. Influencing relatives to respect donor autonomy: Should we nudge families to consent to organ donation? Bioethics 32(3):155-163.

Shepherd, Lee, Ronan E O’Carroll and Eamonn Ferguson. 2014. An international comparison of deceased and living organ donation/transplant rates in opt-in and opt-out systems: a panel study. BMC Medicine 12:131.

Sile’n, Marit, Mia Svantesson, Sofia Kjellstro“m, Birgitta Sidenvall and Lennart Christensson. 2011. Moral distress and ethical climate in a Swedish nursing context: perceptions and instrument usability. Journal of Clinical Nursing 20: 3483-3493.

Slote, Michael. 2007. The Ethics of Care and Empathy. Routledge.

Smajdor, Anna, Andrea Sto“ckl and Charlotte Salter. 2011. The limits of empathy: problems in medical education and practice. J Med Ethics 37:380-383. doi:10.1136/jme.2010.039628

Sque, Magi and Tracy Long-Sutehall. 2011. Bereavement, decision-making and the family in organ donation In Organ Shortage: Ethics, Law and Pragmatism, eds. Anne-Maree Farrell, David Price and Muireann Quigley, 67-85. Cambridge, UK: Cambridge University Press.

Sque, Magi, Wendy Walker, and Tracy Long-Sutehall. 2014. Research with bereaved families: A framework for ethical decision-making. Nursing Ethics 21(8): 946-955. 
Sque, Magi, Wendy Walker, Tracy Long-Sutehall, Myfanwy Morgan, Gurch Randhawa, and Amanda Rodney. 2018. Bereaved donor families' experiences of organ and tissue donation, and perceived influences on their decision making. Journal of Critical Care 45: 82-89.

Taking Organ Transplantation to 2020: A detailed strategy NHSBT (2014)

Taylor, Lauren J, Anne Buffington, Joseph R. Scalea, Norman Fost, Kenneth D. Croes, Joshua D. Mezrich, Margaret L. Schwarze.2018. Harms of unsuccessful donation after circulatory death: An exploratory study. Am J Transplant 18:402-409.

Tenbrunsel, Ann E, Kristin Smith-Crowe, and Elizabeth E. Umphress. 2003. Building Houses on Rocks: The Role of the Ethical Infrastructure in Organizations. Social Justice Research 16(3):285-307.

The European Donor Hospital Education Programme (EDHEP): addressing the training needs of doctors and nurses who break bad news, care for the bereaved, and request donation

The Global Observatory on Donation and Transplantation WHO-ONT (Global Observatory on Donation and Transplantation, 2016) <http://www.transplant-observatory.org/> accessed 10 April 2019

Tong, Rosemarie and Williams, Nancy, "Feminist Ethics", The Stanford Encyclopedia of Philosophy (Winter 2018 Edition), Edward N. Zalta (ed.), URL = $<$ https://plato.stanford.edu/archives/win2018/entries/feminism-ethics/> accessed 10 April 2019

Tronto Joan C. 1993. Moral Boundaries: a political argument for an ethic of care. New York, US: Routledge.

van Dalen, Hendrik P, and Kène Henkens.2014. Comparing the effects of defaults in organ donation systems. Social Science \& Medicine 106: 137-142.

Verheijde, Joseph L, Mohamed Y. Rady, Joan L. McGregor, and Catherine FriederichMurray. 2009. Enforcement of presumed-consent policy and willingness to donate organs as 
identified in the European Union Survey: The role of legislation in reinforcing ideology in pluralistic societies. Health Policy 90: 26-31.

Victor, Bart and John B. Cullen. 1988. The Organizational Bases of Ethical Work Climates. Administrative Science Quarterly 33(1): 101-125.

Waldrop, Deborah P, Judith A. Tamburlin, Sanna J. Thompson and Mark Simon. 2004. Life and Death Decisions: Using School-Based Health Education to Facilitate Family Discussion about Organ and Tissue Donation. Death Studies 28(7): 643-657.

Walker, Wendy, and Magi Sque.2016. Balancing hope and despair at the end of life: The contribution of organ and tissue donation. Journal of Critical Care 32: 73-78.

Walker, Wendy, Andrew Broderick and Magi Sque.2013. Factors Influencing Bereaved Families' Decisions About Organ Donation: An Integrative Literature Review. Western Journal of Nursing Research. 35(10):1339-1359.

Wispelaere, Jurgen De and Lindsay Stirton. 2010. Advance commitment: an alternative approach to the family veto problem in organ procurement. $J$ Med Ethics36:180-183.

Wu, Xiaoliang and Qiang Fang. 2013. Financial compensation for deceased organ donation in China. J Med Ethics 39(6): 378-379. 